\title{
CONCEITOS E ENFOQUES DOMINANTES NA GESTÃO HÍDRICA DO OASIS NORTE DA PROVÍNCIA DE MENDOZA - ARGENTINA
}

Virgínia Grosso

Resumo: Mendoza, província árida do centro-oeste da República Argentina, viveu nos últimos tempos 0 aprofundamento do debate sobre a problemática da escassez de água. Este trabalho tem por objetivo aproximar-se das respostas às seguintes perguntas: quais fatores construíram e contróem a denominada escassez hídrica na província? Eles se apresentam de maneira homogênea em todo o território de Mendonça? Para abordá-las, inicialmente se analisam e correlacionam os aportes teóricos da nova economia e cultura da água e da teoria população-recursos em torno da noção de escassez. Em segundo lugar, se identificaram as problemáticas hídricas (de apropriação, gestão e uso) que se observam ao longo da bacia do rio Mendoza.

Palavras Chave: Escassez de água; zonas áridas; apropriação da água; desigualdade; impactos territoriais

\section{ALGUNAS CONCEPTUALI ZACI ONES Y ENFOQUES DOMI NANTES EN LA GESTI ÓN HÍ DRI CA DEL OASIS NORTE DE LA PROVINCIA DE MENDOZA, ARGENTINA}

\begin{abstract}
Mendoza, provincia árida del centro oeste de la República Argentina, ha vivenciado en los últimos tiempos la profundización del debate sobre la problemática de la escasez de agua. Este trabajo tiene por objetivo aproximarse a las respuestas de las siguientes preguntas: ¿qué factores han construido y construyen la denominada escasez hídrica en la provincia? ¿Se presenta de manera homogénea en todo el territorio mendocino? Para abordarlas, primeramente, se analizarán y correlacionarán los aportes teóricos de la nueva economía y cultura del agua y de la teoría poblaciónrecursos en torno a la noción de escasez. Y en segundo lugar, se identificarán las problemáticas hídricas (de apropiación, gestión y uso) que se observan a lo largo de la cuenca del río Mendoza.
\end{abstract}

PALABRAS CLAVES: Escasez de agua, zonas áridas, apropiación del agua, desigualdad, impactos territoriales

\section{NTRODUCCIÓN}

Tradicionalmente, la consideración de las tierras secas ( 1 ) como áreas frágiles y problemáticas ha influido en que su estudio hídrico gire especialmente en torno al análisis biofísico, más que al de las relaciones económicas y sociales que influyen en la apropiación, manejo y uso del agua.
Asimismo, se suele observar un predominio de investigaciones en donde persiste un enfoque de demografía malthusiana en muchas de las reflexiones acerca del vínculo entre los procesos poblacionales y la disponibilidad de agua; de lo cual generalmente, resulta que los incrementos en 
la población siempre exceden a la capacidad de renovación del ciclo hidrológico (VARGAS VELÁSQUEZ, 1998, p. 177). En el marco de estos tradicionales enfoques teóricos, discursos tales como la escasez hídrica, pocas veces se cuestionan y generalmente, impiden identificar cuáles son las verdaderas causas que la generan y los intereses sectoriales que se ocultan en estos argumentos.

Al respecto, Fernando Aguilera Klink menciona, desde hace algunas décadas se puede afirmar que la escasez ya no es física sino social, es decir, generada por la deficiencia o casi inexistente gestión del agua y la escasa o nula gestión del territorio. Si no prestamos atención a estas cuestiones, los aumentos en el suministro de agua siempre serán insuficientes e ineficaces, pues consolidaremos una economía que es insaciable con relación al uso del agua y con su despilfarro (2008, p. 22-23).

Mendoza, provincia árida del centro oeste de la República Argentina, ha vivenciado en los últimos tiempos la profundización del debate sobre la problemática de la escasez de agua, la falta de inversión en infraestructura hídrica, el uso inadecuado por parte de la población y las diferentes actividades económicas, y su consideración como bien público o privado. En el marco de esta coyuntura, este trabajo tiene por objetivo aproximarse a las respuestas de las siguientes preguntas: ¿qué factores han construido y construyen la denominada escasez hídrica en la provincia? ¿Se presenta de manera homogénea en todo el territorio mendocino? ¿Cuáles son sus mecanismos de producción y reproducción? y ¿cuáles son las consecuencias sociales, políticas y territoriales de decir que hay escasez hídrica?
Con el fin de abordar el anterior objetivo, primeramente, se analizarán y correlacionarán los aportes teóricos de la nueva economía y cultura del agua y de la teoría población-recursos en torno a la problemática de la escasez de los recursos (bienes) naturales, en especial del agua. $Y$ en segundo lugar, se identificarán las problemáticas hídricas (de apropiación, gestión y uso) que se observan a lo largo de la cuenca del río Mendoza (2) con el fin de vislumbrar cómo se inserta el argumento de la escasez de agua en este territorio.

\section{PROBLEMATIZACIÓN DE LAS NOCI ONES \\ Del mito de la abundancia al de la escasez de agua}

Vandana Shiva señala que, "todos concuerdan en que el mundo enfrenta una severa crisis de agua. Las regiones con abundancia de agua ahora viven escasez, y las regiones donde el líquido escaseaba ahora se enfrentan a carestías" (2007, p. 30) Se dice que un país enfrenta grave crisis hídrica cuando el agua disponible no llega a 1.000 $\mathrm{m}^{3}$ por persona al año. Cualquier cifra inferior a ésta implica un gran menoscabo de la salud y el desarrollo económico de una nación. De esta forma, la crisis del agua es una de las facetas más penetrantes, aguda e invisible de la devastación ecológica de la Tierra. En 1998, 28 países experimentaron tensión o escasez hídrica y se prevé que esta cifra aumente a 56 para el año 2025; asimismo, se contempla que el número de personas que viven en países sin suficiente agua aumentará de 131 millones en 1990 a 817 millones en el 2025 (I bidem, p.16).

Por su parte, el informe de la ONU 
“Más allá de la escasez: poder, pobreza y crisis mundial del agua", menciona que en el contexto del desarrollo, algunas veces se abusa de la palabra crisis. No obstante, cuando se trata de la cuestión del agua, hay un reconocimiento cada vez más generalizado de que el mundo se enfrenta a una crisis y de que, no afrontarla, ésta podría impedir el desarrollo humano. Es este mismo informe el que advierte que para algunos, esta crisis mundial del agua tiene que ver directamente con situaciones de escasez absoluta del suministro físico y por ello, algunos analistas tratan los desafíos globales del agua como un problema de escasez (2006, p. v y 2).

Estas posturas no son unánimes. Como menciona M. Larbi Bouguerra,

"la escasez es una relación social con las cosas y no una característica inherente a las cosas. Se notará, que el capitalismo sólo puede funcionar basado en el concepto de la escasez. Por lo tanto, hay que ser muy prudente cuando se habla de crisis del agua y buscar siempre a quién puede beneficiar la misma" (2005, p. 69).

Y agrega, citando al ecologista indio A. Agarwal quien declaraba en La Haya en marzo de 2000, que "no hay escasez de agua, y que el remedio a la crisis consiste en poner fin a la mala gestión hídrica" (Ibidem).

La lectura de estos trabajos permite reafirmar la importancia del agua como elemento esencial para la vida humana y para el pleno desarrollo de todos los componentes de la naturaleza. Asimismo, plantea la necesidad de reflexionar sobre los problemas que se tienen en materia de agua, para lo cual es preciso comenzar definiendo si la llamada crisis del agua se refiere realmente a la escasez absoluta del bien hídrico o es, más bien, un problema de acceso e inequidad social.

En función a este interrogante de investigación, se cree que el análisis de los principios teóricos de la nueva economía y cultura del agua, como así también de la teoría población-recursos, pueden ayudar a esclarecer y comprender el panorama hídrico actual.

\section{Aportes teóricos de la nueva economía y cultura del agua}

La visión de la nueva economía y cultura del agua lleva a plantear dos cuestiones centrales: 1) la noción de agua con la que se debería trabajar y las consecuencias que esa noción supone. Esta situación presume un cambio drástico en los modos de tomar las decisiones y llevar a cabo la planificación de los servicios; y 2) cómo potenciar el manejo del recurso, apuntando a un mejor uso, como alternativa a la construcción de más infraestructuras hidráulicas (BALESTRI y SCHULZ, 2004, p. 2-3).

Con respecto a la primera de estas cuestiones, y como menciona Aguilera Klink, existen diferentes perspectivas sobre qué es lo que entendemos por agua o cuál es la noción de agua con la que es más adecuado trabajar si estamos interesados en una gestión renovable de este recurso. Muchos economistas consideran el agua simplemente como un "bien económico" o como un "factor de producción", términos ambos que destacan sólo la dimensión relacionada con las actividades productivas y con su capacidad para generar un valor monetario, identificando así lo monetario con lo económico (1998, p. 1).

Estos economistas olvidan o, aún peor, ignoran que un factor de producción no 
es sólo una entidad física que una empresa adquiere y usa sin ningún tipo de restricciones, sino que es un derecho a usar el recurso de una manera determinada. En otras palabras, la noción de factor de producción depende del marco institucional, siendo éste el que va a configurar la "lista" de acciones y limitaciones en la extracción y uso del recurso (Ibidem, p. 2).

Asimismo, Aguilera Klink menciona que otros especialistas consideran al agua como un activo financiero, mirada que está centrada en una "racionalidad económica" que ignora el contexto social y ambiental en el que está inserta; por lo tanto, es considerada incompatible con la gestión renovable del recurso, puesto que esa noción incorpora el agotamiento del recurso (I bidem, p. 2-3).

Por otra parte, entender el agua como un activo ecosocial, es visualizar la capacidad que tiene el agua de satisfacer todo un conjunto de funciones económicas, sociales y ambientales, tanto de carácter cuantitativo como cualitativo.

“El agua no sólo es esencial para la supervivencia biológica, sino que es una condición necesaria del desarrollo y sostenimiento de la economía y de la estructura social que hacen posible la sociedad. El agua no es sólo una mercancía; es un imperativo central de la supervivencia, sostenimiento, continuidad y vida de la comunidad..." (Utton, 1985, citado por AGUILERA KLINK, 1998, p. 2).

De esta forma, en la medida en la que esta multifuncionalidad es ignorada, se agudiza y se manifiesta con mayor intensidad el conflicto entre las diferentes funciones, encontrándonos ante una nueva clase de escasez que se explicita mediante la incapacidad del recurso de satisfacer dichas funciones.

En consecuencia, esta perspectiva se preocupa por la gestión del agua no como si fuera un elemento aislado sino, al contrario, como la gestión del ciclo hidrológico, es decir,

“...como un sistema abierto (...) El corolario que para la gestión del agua se deriva de este enfoque ya no puede limitarse a aumentar las entradas al sistema sin atender a lo que ocurre dentro del mismo, sino que debe orientarse a reducir 0 retrasar las pérdidas en cantidad y calidad que se producen en su seno" (Naredo, 1997, citado por AGUILERA KLINK, 1998, p.3).

Respecto al segundo ítem que la nueva economía del agua considera central en el análisis hídrico, el manejo del agua, se observa que en la actualidad existen dos perspectivas claramente enfrentadas. Una de ellas plantea la necesidad de generar numerosas infraestructuras que aumenten el suministro de agua, denominada "vieja economía del agua" o "economía expansionista" (más agua, más infraestructura). La otra, la "nueva economía del agua", insiste en gestionar realmente el agua antes de dar plena preponderancia a la construcción de nuevos embalses y trasvases. La elección por una u otra postura está íntimamente relacionada con la noción de agua que se tenga. En síntesis, se puede decir que mientras la vieja economía del agua da importancia a la generación de oferta hídrica, la nueva economía del agua trata de gestionar inicialmente la demanda para luego centrarse en una gestión integrada de cuencas.

En el marco de los postulados aportados por la nueva economía del agua, 
se considera que la escasez hídrica posee un elevado componente social más que físico. Es el propio comportamiento en el uso y gestión del agua el que agrava dicha escasez y la convierte en una escasez económica y socialmente provocada, por lo que una política hidráulica que descansa principalmente en la construcción de nuevos embalses es bastante limitada ya que no parece enfrentarse a las causas principales de la escasez.

$$
\text { Como sostiene Alejandra Peña }
$$

García,

\begin{abstract}
"hablar del agua como un elemento no sólo natural sino social, lleva a entender que la naturaleza se presenta a través de un trasfondo ideologizado que comúnmente oculta la inequidad social presente en el uso y distribución social de los recursos naturales. A este fenómeno Alfred Schmidt lo identifica como "la ideología de la naturaleza". Desarticular la ideología de la naturaleza significa "desnaturalizarla" para mostrar que su distribución, escasez, contaminación, propiedad y uso son productos sociales que surgen de contextos particulares y que sirven a fines de poder específicos que deben ser cuestionados (2007, p. 130-131).
\end{abstract}

Ahora bien, ser conscientes de esta ideología de la naturaleza permite también visualizar que una gestión hídrica muy abocada y pendiente al comportamiento de la demanda, no es muy acertada, ya que como menciona Aguilera Klink,

“..con frecuencia las pérdidas de agua en la red de distribución suelen ser importantes, sin embargo, las mismas se suelen disfrazar de elevados consumos calificando a los usuarios de derrochadores y disfrazando así a los gestores de las empresas privadas o públicas, su auténtica responsabilidad" (1998, p.5).
La cita anterior refleja que las limitaciones en la gestión hídrica también se presentan cuando sólo se acude a la demanda. Al involucrar y contemplar la demanda en los estudios científicos como en la gestión hídrica, se debe ser consciente por un lado, que para que el capitalista tenga éxito en la tarea de acumular capital, alguien, en algún lugar, debe generar una demanda efectiva (una necesidad); y por otra parte, que la consideración de la demanda en torno al agua, involucra factores demográficos (poblacionales), culturales, políticos y económicos, los cuales no deben ser abordados con ligereza.

Reflexiones a partir del análisis de la relación población-recursos

David Harvey, en su trabajo "La población, los recursos y la ideología de la ciencia", introduce el análisis de las consecuencias políticas de la teoría población-recursos, haciendo mención a un suceso ocurrido en la Conferencia de Estocolmo de 1972. En una de sus reuniones, la delegación china afirmó que no existía nada parecido a la escasez de recursos, y que era absurdo hablar de los problemas medioambientales en dichos términos. Dicho esto, los comentaristas occidentales se desconcertaron y algunos concluyeron que los chinos debían de poseer enormes reservas de minerales y combustibles fósiles cuyo descubrimiento no debían de haber comunicado todavía al mundo. Pese al asombro de toda la conferencia, el autor afirma que la opinión china es bastante consecuente con el método de Marx y debería considerarse desde dicha perspectiva. Para dilucidarlos, el autor propone que introduzcamos en nuestro vocabulario 3 categorías de pensamiento (2007, p. 74): 
-Subsistencia: Malthus la considera como algo absoluto, mientras que Marx lo hace como algo relativo. Para éste último, las necesidades no son puramente biológicas; están también social y culturalmente determinadas. Esto supone que la subsistencia se define entonces internamente al modo de producción y cambia a lo largo del tiempo.

-Recursos: son materiales disponibles "en la naturaleza" y susceptibles de ser transformados en cosas útiles para el hombre. Desde hace tiempo se reconoce que los recursos sólo se pueden definir con respecto a una determinada fase de desarrollo técnico, cultural e histórico, y que son, en efecto, evaluaciones técnicas y culturales de la naturaleza

-Escasez, a menudo se acepta erróneamente que es inherente a la naturaleza, cuando muchas de las escaseces que experimentamos no surgen de ésta sino que son creadas por la actividad humana y gestionadas por la organización social. Además agrega que la escasez es de hecho necesaria para la supervivencia del modo de producción capitalista, y tiene que gestionarse cuidadosamente, ya que de lo contrario el aspecto autorregulador del mecanismo de precios se vendrá abajo (Ibidem, p. 75).

El autor considera que provistos de estas definiciones, se considere una frase simple: “La superpoblación surge por la escasez de recursos disponibles para cubrir las necesidades de subsistencia de la masa de la población". Si se introduce las definiciones en esta frase, tenemos: "hay demasiada gente en el mundo porque los fines determinados que tenemos en mente (junto con la forma de organización social que tenemos) y los materiales disponibles en la naturaleza, que nosotros tenemos la voluntad y la manera de usar, no bastan para proporcionarnos las cosas a las que estamos acostumbrados". De dicha frase se pueden extraer posibilidades de todo tipo: 1) cambiar los fines que se tienen en mente y alterar la organización social de la escasez; 2) cambiar las evaluaciones técnicas y culturales que se hacen de la naturaleza; 3) cambiar los puntos de vista respecto a las cosas a las que se están acostumbrados y 4) intentar alterar las cifras (I bidem).

Una verdadera preocupación por los asuntos medioambientales exige que se examine la relación entre las 4 opciones, sin embargo, el autor afirma que buena parte del debate que se mantiene en el mundo occidental se concentra en la opción 4. El problema de centrarse exclusivamente en el control de las cifras de población es que tiene ciertas consecuencias políticas, ya que en cuanto las connotaciones de límites absolutos llegan a rodear los conceptos de recursos, escasez y subsistencia, se establece un límite absoluto para la población, ¿y cuáles son las implicancias políticas de decir que hay "escasez de recursos"? Tal argumento actúa como poderosa palanca ideológica para persuadir a la no elite de que acepten la situación existente y el establecimiento de medidas autoritarias para mantenerla (HARVEY, 2007, p. 75-78).

En la misma línea, Erik Swyngedouw presta una atención particular a las relaciones de poder sociales y discursivas que amparan el concepto de escasez. Según este autor, la producción discursiva de la «escasez» (SWYNGEDOUW, 2004, p. 47) sirve para manufacturar una crisis social en el terreno 
político de discusión de la gestión del agua y, en última instancia, para apoyar la especulación, que Swyngedouw equipara a un «terrorismo del agua» (MEERGANZ VON MEDEAZZA, 2005, p. 135). Y el autor completa,

\begin{abstract}
“De hecho, la escasez relativa transmitida como un fenómeno absoluto, permite culpabilizar a la fatalidad «natural». Simultáneamente, estas armas discursivas permiten atribuir la escasez relativa a la insuficiente capacidad de producción y/o a la falta de recursos financieros. Ambos ayudan a encauzar el descontento potencial en un discurso tecnocrático, que privilegia las soluciones a la escasez de carácter ingenieril. Sin embargo, con estas soluciones se pierden los usos y los simbolismos populares del agua y también el control popular sobre ésta última" ( bidem).
\end{abstract}

Ahora bien, es cierto que muchas veces, el discurso en torno a la situación hídrica y su solución, dificulta entender realmente cuál es la lógica y los intereses que subyacen en las decisiones que se toman. De esta forma, argumentos referentes al crecimiento de la población, la escasez de recursos y similares pueden surgir por razones bastante dispares y tener impactos muy diversos. Por ello, es crucial determinar los orígenes y los impactos políticos y sociales de los mismos (HARVEY, 2007, p. 79).

Luego de examinar las diferentes posiciones epistemológicas, teóricoconceptuales, metodológicas y/o políticas que existen en torno a la noción de escasez de recursos (bienes) naturales; se pretende identificar las problemáticas hídricas (de apropiación, gestión y uso) que se observan a lo largo de la cuenca del río Mendoza, con el fin de vislumbrar cómo se inserta el argumento de la escasez de agua en este territorio.

\section{CUANDO EL TERRITORIO DENUNCIA}

\section{I dentificación de las problemáticas}

Las zonas áridas y semiáridas de América del Sur alcanzan el $23 \%$ de la superficie y en países como la Argentina, estas áreas abarcan el 75\% del territorio nacional. Mendoza, provincia del centro oeste del país, no es ajena a los escenarios de aridez. Se localiza en la zona templada y en la denominada "Diagonal Árida Sudamericana", por lo que posee un clima árido a semiárido con un promedio de precipitaciones de $200 \mathrm{~mm}$ anuales y un 97\% de tierras secas. De esta forma, los aportes hídricos que se utilizan en los oasis provienen casi en su totalidad de la fusión de las nieves y glaciares ubicados en la Cordillera de los Andes (THERBURG, et al, 2004, p. 24).

Los ríos que nacen en la cordillera han definido importantes cuencas, con grandes centros urbanos y superficie bajo riego. Los tres oasis irrigados con mayor importancia económica, en relación a la población que la habita y a la superficie que se riega son: a) el oasis Norte formado por el río Mendoza y Tunuyán Inferior; b) el oasis Centro formado por el Tunuyán Superior y c) el oasis Sur formado por el río Diamante y Atuel (Fig. 1). 


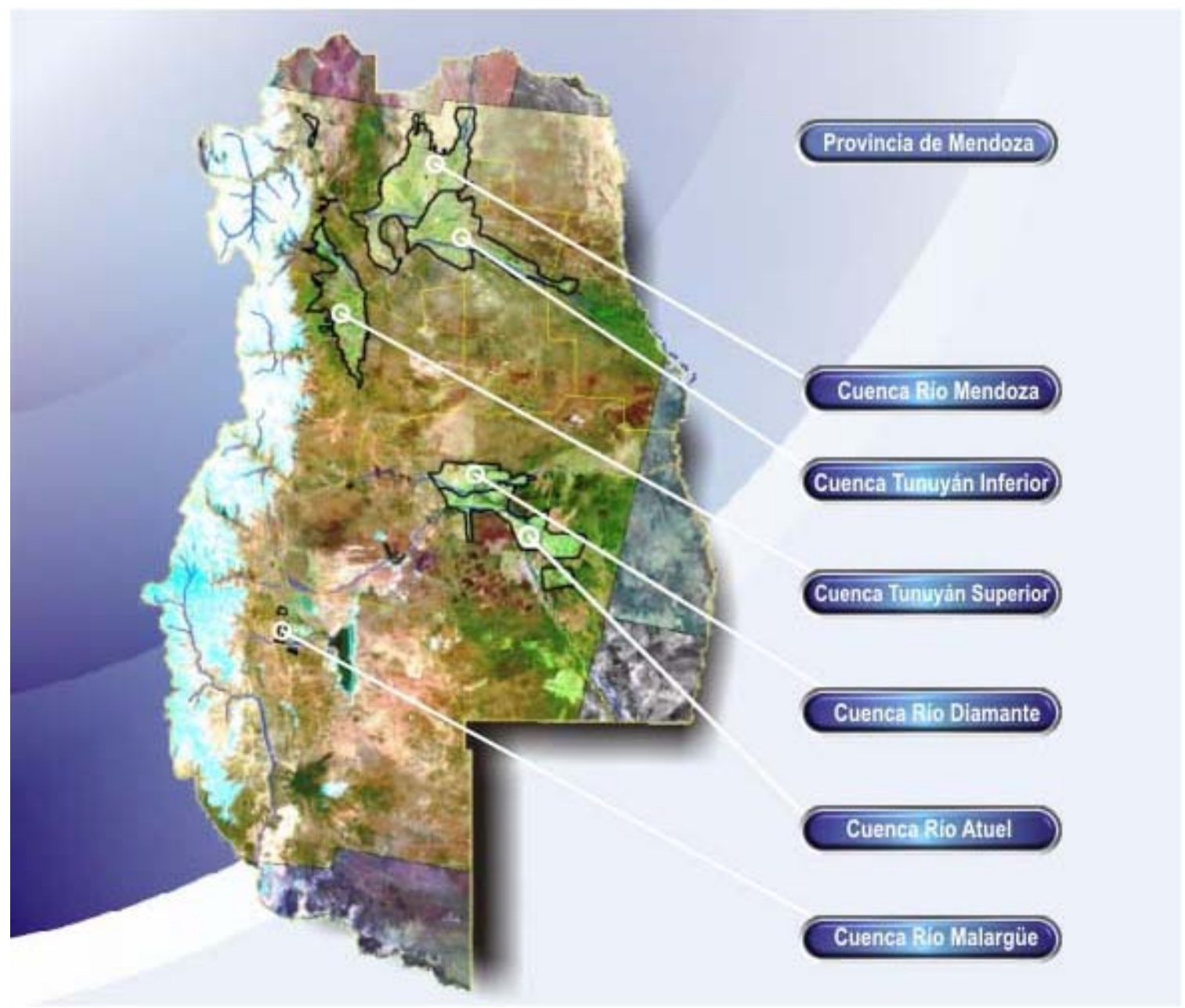

Fig. 1. Cuencas hídricas de la provincia y sus correspondientes oasis de regadío (Fuente: www.irrigacion.gov.ar).

En este contexto, el manejo del agua en Mendoza produce un territorio claramente fragmentado en el que los oasis artificiales de riego ocupan sólo un 3\% de la superficie de Mendoza. Como puede observarse en la Fig. 1, los oasis aparecen como "islas verdes" en un vasto "océano pardo y desértico". En las tierras secas irrigadas (oasis), el $98,5 \%$ de un total de 1.579.651 habitantes que viven en la provincia, practica sus actividades conformando núcleos agrourbanoindustriales. El resto del territorio provincial, aproximadamente el $97 \%$ de la superficie, es una zona de planicies desérticas y cordones montañosos donde habita el $1,5 \%$ de la población (THERBURG, et al, 2004, p. 5-9).

La explicación de tan marcada fragmentación territorial se encuentra, principalmente, en la sistematización del riego, es decir, en la apropiación y manejo de los caudales de los ríos mendocinos y de los acuíferos por parte de un determinado grupo social; y en segundo término, en las aptitudes edáficas. Puesto que el agua es el factor limitante más severo, el riego artificial 
es el principal medio para valorizar las tierras secas y uno de los principales factores del ordenamiento territorial (MONTAÑA, et al, 2005, p. 28).

Por ello, cuando el aprovechamiento de las fuentes hídricas en zonas áridas permite el desarrollo de actividades económicas plenamente integradas al mercado (como la emblemática actividad vitivinícola), éstas suelen darse bajo un patrón de fragmentación territorial: unas pocas y limitadas superficies (las que alcanzan a ser irrigadas artificialmente) se transforman en oasis de agua y de riqueza, en enclaves de desarrollo en medio de vastas zonas pobres y marginales. El agua se convierte así, en recurso de disputa con corolario en el territorio (Foto $\mathrm{N}^{\circ} 1$ ).

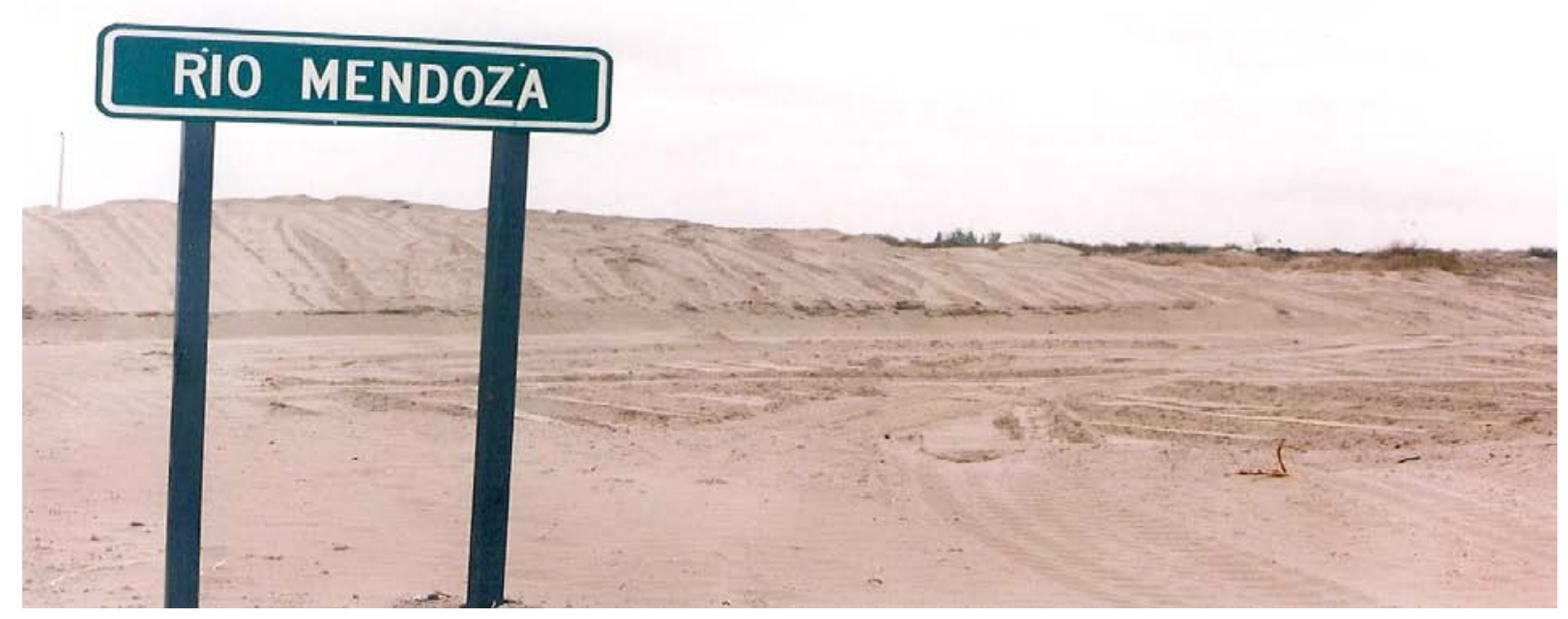

Foto 1. Tramo inferior del río Mendoza, departamento de Lavalle (Fuente: Virginia Grosso, 1997).

De esta forma, el marcado desequilibrio territorial y la falta de equidad social entre las tierras secas irrigadas (oasis) y las tierras secas no irrigadas (desierto), fue identificado como el principal problema de la provincia de Mendoza en el Foro “Desarrollo sustentable de las tierras secas de Mendoza" del 19 de marzo de 2010, organizado en el marco de la Segunda Fase del Plan Estratégico de la Ley $\mathrm{N}^{\circ} 8.051$ de Ordenamiento territorial y usos del suelo. En la misma dirección, el segundo flagelo reconocido fue la concentración demográfica y de políticas orientadas a la producción y servicios en los territorios del oasis en detrimento de las tierras secas no irrigadas; y en tercer lugar, la visión oasis-céntrica de la mayoría de los habitantes de Mendoza y los tomadores de decisiones. De este modo, las mencionadas problemáticas permiten corroborar la estrecha relación que existe entre agua y territorio en la provincia. 


\section{Los aportes históricos e institucionales en la aproximación a las explicaciones}

La valoración y aprovechamiento del agua es algo que los primeros habitantes de la vera del río Mendoza aprendieron muy pronto debido a las mencionadas características ambientales. Los primeros indicios del uso del agua en la zona norte de Mendoza, están referidos a productos agrícolas cultivados por un grupo importante de nativos denominados huarpes (FERNÁNDEZ, 2006, p. 33-34).

Luego, la dominación española en el siglo XVI, determinó la primera gran reconversión productiva de la zona. A lo largo de la etapa colonial, el Oasis Norte irá concentrando su producción en torno a por un lado, el cultivo bajo riego de cereales y engorde de ganado para su venta a Chile y por el otro, la fabricación de alcoholes y vinos. De esta forma, comienza en esta etapa el desarrollo de un sistema cultural hegemónico identificado con el oasis que, en paralelo, va limitando el desarrollo del resto del territorio que cada vez más comienza a funcionar como sistema subordinado (MONTAÑA, et al, 2005, p. 16-17).

La valorización del agua como recurso estratégico para el desarrollo de las actividades humanas fue precoz y la institucionalización de esta visión del recurso se concretó tempranamente en la Ley de Aguas de 1884. Los avances institucionales y legales respecto de los recursos hídricos fueron claves en la reconversión de la economía provincial de fines del siglo XVIII y principios del XIX. El pasaje de una economía pastoril- ganadera que exportaba ganado en pie a Chile a una economía vitivinícola destinada a abastecer el creciente mercado interno argentino requería de la ampliación de la frontera agraria. La misma fue posible a través de la sistematización del agua en el tramo medio de la cuenca del río Mendoza (Ibidem, p. 15), desarrollada en su mayoría, por el sector privado de la provincia (CHAMBOULEYRON, 2004, p. 119).

Los impactos espaciales fueron importantes. Como corazón del Oasis Norte, la ciudad de Mendoza registró un crecimiento importante y comenzó a evidenciarse la competencia de los usos urbanos y los agrícolas, aunque esto no era relevante en tiempos de plena expansión de la frontera agraria. Pero esta expansión (urbana y agrícola) incrementaba la demanda de agua; el mayor aprovechamiento de los caudales efectuados en el Oasis Norte, en el curso medio del río, comenzó a restringir los débitos que llegaban al departamento de Lavalle, en el tramo inferior (MONTAÑA, et al, 2005, p. 19). Como menciona Chambouleyron,

"A partir del siglo XIX se desarrolló tanto el uso del agua y el aprovechamiento de las tierras, que su uso fue caótico (...) Era común la queja de los usuarios de las zonas bajas del río Mendoza por la imposibilidad de derivar el agua debido a que toda quedaba en las zonas altas" (2004, p. 131).

De esta forma, el discurso oficial relata que las últimas décadas del siglo XVIII y las primeras del XIX pertenecen a los "domadores del desierto", quienes efectuaron un rico despliegue de recursos técnicos, institucionales, organizacionales, legales y políticos para la construcción del llamado "modelo vitivinícola tradicional". Sin embargo, esa misma historia muchas veces olvida relatar las consecuencias ambientales 
(áreas irrigadas devenidas a desiertos) y sociales (marginalidad, abandono) que padecieron los habitantes del curso inferior del río, los “aguas abajo". En ellas, no sólo se perdió dinamismo económico por una merma en los caudales hídricos, sino que se incrementaron las actividades extractivas, como la tala de algarrobos que se destinó a satisfacer las demandas de madera y carbón para la ciudad de Mendoza y para la actividad vitivinícola (MONTAÑA, et al, 2005, p. 20).

La mitad de la década de los setenta del siglo $\mathrm{XX}$, aparece como el comienzo de la gran y definitiva crisis del modelo vitivinícola tradicional. Esta actividad económica estaba totalmente centrada en el mercado interno argentino, el cual se encontraba en franco retroceso amenazado por cambios en los hábitos de consumo. La alternativa exportadora era inviable con el perfil de la producción regional escasamente diversificada, por lo tanto, en los años ochenta, se llega a un cierto consenso en la sociedad mendocina sobre la necesidad de "reconvertir" la actividad vitivinícola. De esta forma, en la década de los noventa se consolida una "nueva vitivinicultura" que se orienta a la calidad y la exportación (I bidem, p. 20-23).

A raíz de esta reconversión, se suscitaron múltiples transformaciones, por un lado, numerosos pequeños agentes de la vitivinicultura local no pudieron reconvertirse y en muchos casos, no sobrevivieron a la crisis, por lo que se vieron en la obligación de abandonar sus cultivos, en pos de la urbanización, o peor aún, de la mera especulación inmobiliaria. “Estos espacios resultantes, productos de una coyuntura económica, pueden ser considerados procesos de desertificación al interior del oasis" (Ibidem, p. 23-24).

Por otro lado y de manera opuesta, el dinamismo de la nueva vitivinicultura empezó a ampliar sus fronteras hacia zonas de mejores condiciones agroecológicas, particularmente de la mano de agentes extranjeros quienes prefieren producir tierras altas ganadas al desierto a modernizar los viñedos de zonas de antigua ocupación y en las partes más bajas de la cuenca. De esta forma, los frentes pioneros de la renovada vitivinicultura avanzan sobre los terrenos vírgenes de los piedemontes, a partir del uso de agua subterránea, dejando tras de sí viejas zonas de los oasis crecientemente degradadas y en camino hacia la desertificación (Ibidem).

Ajenos a la dinámica vitivinícola y cada vez más alejados de las actividades exportadoras, las tierras secas no irrigadas constituyen una prueba clara, en esta etapa, de los efectos de un largo proceso de pérdidas en el control de sus riquezas, situaciones que terminan frenando las posibilidades de desarrollo del área (MONTAÑA, et al, 2005, p. 24). Es que como bien menciona Triviño, $L$, “ese $4 \%$ del territorio, fue y es en términos generales, el escenario del protagonismo histórico mendocino, el epicentro de las decisiones políticas y económicas..." (2004, p. 147).

De esta forma, se observa que el marco normativo en materia hídrica permitió la organización de la administración del agua y el desarrollo territorial bajo una perspectiva acorde al modelo agrícola irrigado tradicional de fines del siglo XIX (Foro "Desarrollo sustentable de las tierras secas", 2010) de cara al oasis y de espaldas a las tierras secas no irrigadas, que debe ser modificado 
teniendo en cuenta la equidad ambiental, social y económica.

CONSI DERACI ONES FI NALES. En

\section{el camino...}

¿Cómo se inserta el argumento de la escasez en estas tierras? El análisis de las características ambientales y de la historia de la cuenca del río Mendoza, desde lo territorial y normativo, permitió vislumbrar que Mendoza es actualmente un espacio fragmentado, vertebrado en torno a profundas contradicciones. Estas contradicciones, analizadas en su expresión territorial, vuelven evidentes "trazas" en las que los factores del medio natural, impactantes en una primera mirada, resultan menos importantes frente a explicaciones en torno al poder y las cadenas de dominación (MONTAÑA, et al. 2005, p. 11).

La mencionada inequidad en el acceso hídrico entre las poblaciones ubicadas "aguas arriba" y "aguas abajo" de la cuenca hidrográfica, parece estar mostrando la acumulación de los efectos negativos derivados de modelos de desarrollo y actividades económicas para los cuales el agua es simplemente un activo económico, un factor más de la producción. Esta perspectiva impide entender el agua como un activo ecosocial, visualizar la capacidad que posee para satisfacer todo un conjunto de funciones económicas, sociales y ambientales, tanto de carácter cuantitativo como cualitativo. De esta forma, en la medida en la que esta multifuncionalidad es ignorada, se agudiza el conflicto entre las diferentes funciones, encontrándonos ante una nueva clase de escasez que se explicita mediante la incapacidad del recurso de satisfacer dichas funciones.
Al respecto, Harvey plantea una oportuna relación entre la noción de escasez y el territorio. El autor menciona que,

"el concepto de escasez no es fácil de comprender, aunque lo utilicemos constantemente cuando hablamos de la asignación de recursos escasos. Por ejemplo, es discutible la existencia de una escasez surgida de modo natural (...) La escasez ha de ser producida y controlada en la sociedad, porque de otro modo el mercado de precios no funcionaría (...) Si aceptamos que el mantenimiento de la escasez es esencial para el funcionamiento del sistema de mercado, aceptaremos entonces que la privación, la apropiación y explotación son consecuencias necesarias del sistema de mercado. En un sistema espacial, esto significa que habrá una serie de movimientos de apropiación entre territorios que hará que algunos territorios sean explotadores y otros explotados" (1977, p. 116).

Por otra parte, el análisis de las

diversas posturas teóricas en torno a la escasez de agua permitió ser conscientes de la multidimensionalidad del agua y de su complejidad. Como menciona Peña García, A,

"la naturaleza hoy en día, está lejos de ser sólo aquella materia originaria producto de millones de años de evolución, algo ya dado, un ente con cualidades inherentes e inmutables, sometida a una dinámica cuyo carácter esencial puede ser objetivamente estudiado, es decir, como ámbito aislado de la sociedad. Las cualidades de la naturaleza que en un momento particular se consideran relevantes no son inmutables sino más bien contingentes a las prácticas sociales, por lo que nombrar a la naturaleza y adjudicarle toda una variedad de adjetivos, necesariamente está enérgicamente condicionado por un modo específico de producción, y se lleva a cabo desde cierta posición cultural y política determinada" (2007, p. 130).

Al igual que el agua, elemento multidimensional por naturaleza, se entiende 
a la realidad y al conocimiento científico como un proceso constructivo evolutivo en donde intervienen diversas variables de análisis, desde los aspectos históricos, sociológicos, psicológicos y en este caso, territoriales. Por ello, se es consciente que todas las preguntas planteadas al inicio del trabajo no han podido ser contestadas en estas páginas; sin embargo, este abordaje permitió dar el primer paso en el análisis de la escasez de agua en la cuenca del río Mendoza, es decir, problematizar acerca de este argumento, concepto que es sobre-utilizado en los problemas de agua de las tierras secas.

\section{NOTAS}

1. Se entiende por tierras secas a aquellos territorios (espacios y sociedades) en los que existe stress hídrico, o sea en donde las magras precipitaciones son inferiores a la cantidad total de agua evaporada a la atmósfera (se excluyen las zonas polares y de nieves eternas). En general son clasificadas como zonas semiáridas, áridas y desiertos y están definidas en función a las precipitaciones (FERNÁNDEZ CIRELLI y ABRAHAM, 2002, p. 7).

2. Esta cuenca es la más problemática de la provincia debido a su concentración demográfica y económica y a su extensión en superficie. La misma sirve con sus aguas a las áreas urbanas y rurales irrigadas de 7 departamentos (el Oasis Norte) y contiene, además, el mayor aglomerado urbano y primera metrópolis regional del oeste argentino, el Área Metropolitana de Mendoza.

\section{Referências Bibliográficas}

AGUILERA KLINK, Federico. Hacia una nueva economía del agua: cuestiones fundamentales. Departamento de Economía Aplicada. Universidad de la Laguna. Tenerife, España. 1998. 158 págs.

BALESTRI, Luis y SCHULZ, Carlos. El paradigma económico vigente en algunos prestadores de servicio de agua en el norte de La Pampa. 2004.

CHAMBOULEYRON, Jorge. "La cultura del agua: de la acequia colonial a los grandes embalses. En: ROIG, Arturo; LACOSTE, Pablo y SATLARI, M.Cristina (comp). Mendoza, cultura y economía. Ed. Caviar Bleu, Mendoza, Argentina. 2004, 115-144.
FERNÁNDEZ, Liliana. “Diagnóstico de la situación del agua en la provincia de Mendoza". En: Defensoría del agua y los derechos humanos. Informe de situación. Mendoza, Argentina. 2006.

FERNÁNDEZ CIRELLI, Alicia y ABRAHAM, Elena. (ed.) El agua en Iberoamérica. De la escasez a la desertificación. CYTED XVII. Aprovechamiento y gestión de recursos hídricos. Argentina. 2002. 167 págs.

HARVEY, David. Espacios del capital. Hacia una geografía crítica. Ed. Akal SA. Madrid, España. 2007. 447 págs.

MEERGANZ VON MEDEAZZA, Gregor. “Flujos de agua, flujos de poder. La aportación de 
Erik Swyngedouw al debate sobre los recursos hídricos en Latinoamérica y en el Estado español". En: Doc. Anàl. Geogr. 47, España. 2006. 129-139.

MOHAMED LARBI BOUGUERRA. Las batallas del agua. Por un bien común de la humanidad. Ed. Popular, SA. Madrid, España. 2005. 238 págs.

MONTAÑA, Elma; TORRES, Laura; ABRAHAM, Elena; TORRES, Eduardo; PASTOR, Gabriela. “Los espacios invisibles. Subordinación, marginalidad y exclusión de los territorios no irrigados en las tierras secas de Mendoza, Argentina". En: Revista Región y Sociedad. Vol. XVII, N³2. México. 2005. 1-32.

ONU. “Más allá de la escasez: poder, pobreza y crisis mundial del agua. Informe de Desarrollo Humano". 2006. Disponible en: http://hdr.undp.org/en/reports/global/hdr200 6/

PEÑA GARCíA, Alejandra. “Una perspectiva social de la problemática del agua". En: Investigaciones Geográficas. Boletín del Instituto de Geografía, UNAM. N $N^{\circ} 62$, 2007.125-137.

SHIVA, Vandana. Las guerras del agua. Privatización, contaminación y lucro. Ed. Siglo XXI. 2007. 163 págs.
SWYNGEDOUW, Erik. Social Power and the Urbanization of Water: Flows of power. Oxford: Oxford University Press. 2004.

THERBURG, Almut; FASCIOLO, Graciela; COMELLAS, Eduardo; ZULOAGA, José y GUDIÑO, M.Elina. Marco estratégico para la provincia de Mendoza. Diagnóstico físicoambiental. UNCuyo, Mendoza. 2004. 88 págs.

TRIVIÑO, Luis. “Mendoza desértica” En: ROIG, Arturo; LACOSTE, Pablo y SATLARI, M.Cristina (comp). Mendoza, cultura y economía. Ed. Caviar Bleu, Mendoza, Argentina. 2004, 145173.

VARGAS VELÁSQUEZ, Sergio. “El uso del agua: un enfoque crítico de la relación población-ambiente-recursos" En: Papeles de población, enero-marzo, número 15. Universidad Autónoma del Estado de México. Toluca, México. 1998. 17-192. 